\title{
DOCUMENTOS E ORIENTAÇÕES PARA REGULARIZAR A EESJ: UMA CONTRIBUIÇÃO À EDUCAÇÃO PENITENCIÁRIA ${ }^{1}$
}

\author{
Zenilda Rodrigues Dias \\ Eliane Leal V asquez.
}

\section{INTRODUÇÃO}

Este capítulo analisa os documentos e as orientações para regularizar uma escola pública no Conselho de Estado de Educação, órgão da Secretaria de Estado da Educação - CEE-AP/SEED, no Estado do Amapá. Nessa perspectiva, o trabalho toma como base a Lei de Diretrizes e Bases da Educação Nacional - LDBN, a Lei de Execução Penal - LEP, as Diretrizes Nacionais para Educação em Estabelecimentos Penais e a lei que instituiu o Plano Estratégico de Educação no âmbito do Sistema Prisional - PEESP (BRASIL, 2009; 1996; 1984; 2011), além de outras referências, leis e resoluções do Brasil e do Amapá, e ainda, informações sobre os professores que trabalham na Educação de Jovens e Adultos na Educação Penitenciária - EJA/EP, na cidade de Macapá.

O estudo foi desenvolvido com base no problema: Quais os atos oficiais de regularização e os documentos que a Escola Estadual São José - EESJ possui? A escola de acordo com os critérios da legislação educacional, está em situação regular ou irregular no CEE-AP?

Optamos em usar neste trabalho o termo - Educação Penitenciária, para reconhecer as especifidades de uma escola que funciona dentro da prisão, como é o caso da EESJ, numa perspectiva que a defende para promover a Cultura de Paz, Inclusão Social e Cidadania, considerando que a educação é um direito social e humano, conforme a concepção de educação das duas versões do Plano Estadual de Educação para o Sistema Penitenciário Amapaense - PEESP/AP (AMAPÁ, 2014, 2017).

E ao mesmo tempo para continuar provocando a reflexão de que a educação penitenciária necessita ser reconhecida como modalidade de ensino no Brasil, como já é na Lei de Educação Nacional de um dos países da América Latina, a Argentina, o que Xavier e Silva (2017) discutiram no artigo "Educação no Cárcere: Análise comparativa das legislações Brasileira e Argentina".

\footnotetext{
${ }^{1}$ DOI: $10.29388 / 978-65-86678-21-5-f .113-140$.
} 


\subsection{Marcos legais e documentos importantes do estudo}

A importância do acesso à educação escolar no sistema penitenciário para o desenvolvimento humano é incontestável, pois os processos educativos orientam e auxiliam o adulto preso na forma de relacionar-se com as outras pessoas com que convive, durante a execução de sentença criminal ou detenção preventiva, além de levá-lo a construir sua própria identidade como participante de uma comunidade escolar.

No contexto de privação de liberdade, no qual se insere o tema deste estudo, são muitas as leis que tratam da educação no Brasil, tanto para pessoas que não foram julgadas pelo Poder Judiciário, como aquelas que foram por terem cometido crimes, dentre as quais citamos, a Constituição Federal - CF, LEP e LDBN (BRASIL, 2006; 1984; 1996), entre outras.

Um grande marco para a História do Brasil e da Educação Brasileira, foi a data de 5 de outubro de 1988, pois o presidente José Sarney promulgou a CF. Com a queda do regime militar, o país estava em processo de redemocratização e uma nova CF passou a vigorar, na qual a educação ganhou seu reconhecimento como parte dos direitos sociais, conforme o Art. $6^{\circ}$ da CF (BRASIL, 2006), assim como a saúde, o trabalho, a alimentação, a moradia, o lazer, a segurança, o transporte, a previdência social, a assistência aos desamparados e à proteção maternidade e à infância.

Já no Art. 205 da CF, a educação é defendida como direitos de todos os cidadãos, sendo deveres do Estado e da família de promovê-la, cabendo à sociedade brasileira incentivá-la para garantir o desenvolvimento pleno das pessoas (BRASIL, 2006).

Contudo, foi a LEP que regulamentou no seu Art. $3^{\circ}$ "Ao condenado e ao internado serão assegurados todos os direitos não atingidos pela sentença ou pela lei. Parágrafo único. Não haverá qualquer distinção de natureza racial, social, religiosa ou política" (BRASIL, 1984). Embora durante a execução da sentença criminal, serem suspensos o direito político da pessoa condenada, conforme determina o Art. $15^{\circ}$ da CF, no seu inciso III (BRASIL, 2006), todos os demais direitos devem ser assegurados, em cumprimento a legislação brasileira.

A LEP refere-se à educação escolar, usando o termo "assistência educacional”, desde a sua primeira edição, conforme os artigos da Seção 5 do Capítulo II: 
Art. 17. A assistência educacional compreenderá a instrução escolar e a formação profissional do preso e do internado.

Art. 18. O ensino de primeiro grau será obrigatório, integrando-se no sistema escolar da unidade federativa.

Art. 19. O ensino profissional será ministrado em nível de iniciação ou de aperfeiçoamento técnico.

Parágrafo único. A mulher condenada terá ensino profissional adequado à sua condição.

Art. 20. As atividades educacionais podem ser objeto de convênio com entidades públicas ou particulares, que instalem escolas ou ofereçam cursos especializados.

Art. 21. Em atendimento às condições locais, dotar-se-á cada estabelecimento de uma biblioteca, para uso de todas as categorias de reclusos, provida de livros instrutivos, recreativos e didáticos (BRASIL, 1984).

Com base na primeira edição da LEP, pode-se concluir que por volta de trinta e um anos, os artigos que regulamentaram a assistência educacional no sistema penitenciário foram somente cinco, considerando que ela sofreu algumas alterações no ano de 2015. Ano que passou a vigorar, a Lei no 13163, que instituiu o ensino médio nas penitenciárias (BRASIL, 2015).

Quanto à educação escolar ou formal, Onofre e Julião (2013, p. 52) advertem e chamam a atenção para o fato de que:

Pensar o universo da educação significa ir além do processo educativo institucionalizado, também denominado educação formal ou escolar, somando-se a ela as experiências educativas que ocorrem no cotidiano das pessoas, através do relacionamento com outras pessoas e com o seu ambiente.

A educação desenvolvida na prisão insere-se em um espaço repressivo, ela potencializa processos educativos para além da educação escolar, pois evidencia os educadores como atores importantes na construção de espaços, em que as pessoas aprisionadas podem ressignificar o mundo como algo dinâmico e inacabado. Em outras palavras, é um fenômeno complexo, pois o contexto prisional revela-se singular, ao mesmo tempo é semelhante aos outros espaços educativos (ONOFRE; JULIÃO, 2013).

Formalmente, no Brasil, a modalidade que oferta cursos para adultos presos é a Educação de Jovens e Adultos - EJA. E também é responsável pela oferta de cursos de ensino fundamental e médio para qualquer pessoa que não 
tenha estudado na idade própria, conforme normatiza o Art. 37 da LDBN (BRASIL, 1996).

No que se refere à EJA em contexto de privação de liberdade, a Resolução CNE/CEB no 02/2010 estabeleceu as Diretrizes Nacionais para a oferta de Educação para Jovens e Adultos em Situação de Privação de Liberdade nos estabelecimentos penais. Essa resolução foi editada pelo Conselho Nacional de Educação (BRASIL, 2010).

Em seguida, a LEP sofreu outras alterações e uma delas ocorreu pela Lei $n^{\circ} 12.433 / 2011$, que regulamentou a remição da pena pelo estudo ou trabalho, de acordo com seu Art. 126:

Art. 126. O condenado que cumpre a pena em regime fechado ou semiaberto poderá remir, por trabalho ou por estudo, parte do tempo de execução da pena.

$\mathbb{S} 1^{\circ}$ A contagem de tempo referida no caput será feita à razão de:

I - 1 (um) dia de pena a cada 12 (doze) horas de frequência escolar - atividade de ensino fundamental, médio, inclusive profissionalizante, ou superior, ou ainda de requalificação profissional - divididas, no mínimo, em 3 (três) dias;

$\mathbb{S} 2^{\circ}$ As atividades de estudo a que se refere o $\mathbb{1 ^ { \circ }}$ deste artigo poderão ser desenvolvidas de forma presencial ou por metodologia de ensino a distância e deverão ser certificadas pelas autoridades educacionais competentes dos cursos frequentados.

$\mathbb{S} 3^{\mathbf{o}}$ Para fins de cumulação dos casos de remição, as horas diárias de trabalho e de estudo serão definidas de forma a se compatibilizarem.

$\$ 4^{\circ}$ O preso impossibilitado, por acidente, de prosseguir no trabalho ou nos estudos continuará a beneficiar-se com a remição.

$\mathbb{S} 5^{\circ} \mathrm{O}$ tempo a remir em função das horas de estudo será acrescido de $1 / 3$ (um terço) no caso de conclusão do ensino fundamental, médio ou superior durante o cumprimento da pena, desde que certificada pelo órgão competente do sistema de educação (BRASIL, 2011).

Mais ainda no ano de 2011, um outro importante decreto foi sancionado pela presidente Dilma Rousseff, o Decreto n 7.626/2011, que instituiu o Plano Estratégico de Educação no âmbito do Sistema Prisional - PEESP, sendo a sua finalidade ampliar e qualificar a oferta de educação nas prisões (BRASIL, 2011).

Vejamos o que seus Art. $2^{\circ}$ e $3^{\circ}$ normatizaram: 
Art. $2^{\circ}$ O PEESP contemplará a educação básica na modalidade de educação de jovens e adultos, a educação profissional e tecnológica, e a educação superior.

Art. $3^{\circ}$ São diretrizes do PEESP:

I - promoção da reintegração social da pessoa em privação de liberdade por meio da educação;

II - integração dos órgãos responsáveis pelo ensino público com os órgãos responsáveis pela execução penal; e

III - fomento à formulação de políticas de atendimento educacional à criança que esteja em estabelecimento penal, em razão da privação de liberdade de sua mãe.

Parágrafo único. $\mathrm{Na}$ aplicação do disposto neste Decreto serão observadas as diretrizes definidas pelo Conselho Nacional de Educação e pelo Conselho Nacional de Política Criminal e Penitenciária (BRASIL, 2011).

Em cumprimento a este decreto, "todos os estados foram compelidos a desenvolverem os respectivos planos estaduais de educação em prisões [...]" (SILVA et al, 2017, p. 73). As elaborações desses planos eram necessárias para captação de recurso financeiro pelos Estados e Distrito Federal do Governo Federal por intermédio do Ministério da Justiça e Educação, para implementação de suas ações conjuntas nas áreas da Educação e da Execução Penal (BRASIL, 2011).

Duarte e Sivieri-Pereira (2018, p. 350) contribuem com a discussão, quando avaliam que o PEESP pode trazer mudança às pessoas privadas de liberdade, ou seja:

A título de elucidação, verificamos (teoricamente) na atualidade maior preocupação com a formação de professores, apoio a abertura de oportunidade de monitoria aos presos em condições intelectuais de auxiliar os professores no processo de ensinagem, incentivo à parceria entre as escolas instituídas nas prisões e as universidades, promoção à equidade em relação às necessidades de inclusão e diversidade de gênero, raça, etnia, credo, idade e condição social das pessoas em privação de liberdade; incentivo à educação na modalidade EaD, apoio à participação da pessoa em privação de liberdade em programas e processos seletivos de ingresso na Educação Superior, como o Exame nacional do Ensino Médio (ENEM), por exemplo, promoção à continuidade dos estudos dos egressos do sistema prisional, entre outras normativas estratégicas que visam à reestruturação dos valores das pessoas em privação de liberdade em conformidade com as regras e limites estabelecidos pela sociedade. 
O Decreto n⿳⺈ 7.626/2011 implicou na necessidade dos Estados e do Distrito Federal de realizarem novos planejamentos para a oferta de cursos às pessoas presas. No Amapá, por exemplo, passou a vigorar a Resolução no 057/2015-CEE/AP (AMAPÁ, 2015), que regulamentou a oferta de cursos de EJA, educação profissional e tecnológica aos adultos presos.

De acordo com o $\$ 1^{\circ}$ do Art. $8^{\circ}$ dessa resolução define com relação a uma parte das competências da SEED: “[...] deverá, por meio de Escola de Referência, garantir a oferta de educação para as pessoas privadas de liberdade, bem como manter toda regularidade da vida escolar dos alunos para todo sistema prisional do Estado" (AMAPÁ, 2015). Ainda, a resolução normatizou no $\$ $2^{\circ}$ do Art. $8^{\circ}$ que, as ações, projetos e programas governamentais destinados à educação de jovens e adultos presos e desenvolvidas nas escolas, deverão ter provimento de materiais didáticos e escolares, equipamentos, apoio pedagógico, alimentação e saúde para seu corpo discente (Ibid., 2015).

O fato da Resolução nº 057/2015-CEE/AP ter sido aprovada, é um indicativo que os estudos realizados pelo Grupo de Trabalho e duas Comissões para elaborar o PEESP/AP, provocou algum desdobramento no CEE, uma vez que, o PEESP/AP é um importante planejamento para execução de serviços educacionais no sistema penitenciário amapaense no futuro (AMAPÁ, 2014; 2015).

A elaboração do PEESP/AP foi iniciada no mês de setembro de 2012, atendendo ao Decreto n⿳ 7.626 de 24 de novembro de 2011, que instituiu o Plano Estratégico de Educação no âmbito do Sistema Prisional (BRASIL, 2011). A primeira versão completa do PEESP/AP foi concluída em 2014, sendo o seu texto aprovado pelos participantes do I Seminário de Políticas Públicas para Educação Penitenciária no Amapá, evento que aconteceu em 28 e 29 de agosto de 2013, na Universidade Federal do Amapá - UNIFAP (AMAPÁ, 2014), na cidade de Macapá.

Com relação a sua revisão preliminar, um fragmento da sua versão mais atualizada, esclarece que:

A revisão preliminar do referido documento foi concluída pela equipe da NEJA/CEESP/SEED, em julho de 2015, com fim de que o mesmo fosse discutido e aprovado na Conferência do Plano Estadual de Educação para o Sistema Penitenciário Amapaense: Da educação à Libertação do Ser, evento que estava planejado a realizar-se de 10 a 14 de agosto de 2015, na cidade de Macapá. O referido evento foi organizado pela Secretaria de Estado da Educação, em parceria com o Serviço Social do Comércio, Secretaria de Estado da Justiça e Seguran- 
ça Pública, e Grupo Políticas Públicas e Educação Inclusiva/Universidade Federal do Amapá (AMAPÁ, 2017, p. 16).

Neste trabalho, também citamos a versão do PEESP/AP (AMAPÁ, 2017), que foi encaminhado pelo Ofício nำ 02/2017-NAI/PROEAC/ UNIFAP à gestora da EESJ (UNIFAP, 2017), pois nesse ano, a mesma solicitou uma cópia da versão do PEESP/AP para Universidade e que foi atualizado após a realização da Conferência do Plano Estadual de Educação para o Sistema Penitenciário Amapaense: Da educação à libertação do ser, evento que aconteceu na Assembleia de Deus, na cidade de Macapá e na Escola Estadual Jesus de Nazaré, em 10 a 14 de agosto de 2015, na cidade de Macapá, organizado pela SEED/AP e seus parceiros.

Também, em 2015, a UNIFAP e seus colaboradores realizaram o II Seminário de Políticas Públicas para Educação Penitenciária no Amapá: Articulando a consolidação das metas do Plano Estadual de Educação para o Sistema Penitenciário Amapaense na Política Educacional, em 10 e 11 de dezembro de 2015, no Campus Marco Zero do Equador, na cidade de Macapá.

Passados dois anos e quatro meses, mais uma vez a UNIFAP, por intermédio do Curso de Teatro e seus apoiadores, realizaram o III Seminário de Políticas Públicas para Educação Penitenciária no Amapá: Arte, Cultura e Educação Penitenciária, integrado à programação do IV Seminário em Artes Cênicas do Amapá, na cidade de Macapá, que aconteceu de 23 a 29 de abril de 2018.

Nesse evento, o Grupo de Trabalho: Criação Coletiva de Documento Público sobre a implantação de Políticas Públicas de Cultura na Educação Penitenciária, foi mediado por Myriam Sylvia Sousa de Almeida e contou com a participação de Emerson de Paula Silva e Eliane Leal Vasquez como debatedores, momento em que foi redigido por essa equipe a primeira Carta da Educação Penitenciária Amapaense. A carta foi produzida com base no debate entre os participantes do grupo de trabalho e das reflexões sobre o fato da demora de aprovação do PEESP/AP pela Assembleia Legislativa do Amapá, sendo a carta aprovada em 27 de abril de 2018 de forma coletiva (ALMEIDA; SILVA; VASQUEZ, 2018).

\subsection{Conhecendo a Resolução no ${ }^{0} 077 / 2014-\mathrm{CEE} / \mathrm{AP}$}

Qualquer escola, seja pública ou privada tem que cumprir as normas para fazer parte do sistema de ensino. Há critérios para infraestrutura do prédio, o Projeto Político Pedagógico, as disciplinas ofertadas, a carga 
horária e o corpo docente, entre outros aspectos. Os seus procedimentos são definidos pelo Conselho Estadual de Educação - CEE/AP, o que destacamos com base na Resolução nº 077/2014-CEE/AP:

Os procedimentos para a regularização da vida escolar devem ser adotados pelos estabelecimentos de ensino devidamente autorizados que recebam alunos com irregularidades em sua vida escolar ou sem essa documentação nas hipóteses previstas em leis e atos normativos do Sistema Estadual de Ensino (AMAPÁ, 2014, p. 1).

Uma instituição de ensino é considerada em situação regular no $\mathrm{CEE} / \mathrm{AP}$, quando seus atos oficiais estão de acordo com todas as normas da Resolução nº 077/2014-CEE/AP ou quando a escola está solicitando ao órgão responsável dentro do prazo definido, ou seja, quando os atos legais estejam próximos de expirar-se e a escola já tenha solicitado a sua renovação.

Quando uma escola está em situação regular, ela tem autonomia para resolver as demandas relacionadas a vida escola de qualquer estudante, bem como tem autorização para expedir qualquer documentação. A regularização da escola no CEE/AP é uma obrigatoridade, e ao mesmo tempo, um critério para captação de recursos financeiros em alguns Programas do Governo Federal e Estadual.

Por outro lado, uma instituição de ensino é considerada em situação irregular, quando os seus atos oficiais estão vencidos ou quando a escola não tem, ou seja, quando os atos legais estão expirados, e ainda, não foi protocolado o seu pedido de renovação. Além de perder a autonomia escolar, as escolas em situação de irregularidade, podem sofrer infração ou punições dos órgãos fiscalizadores, conforme define o Art. 39 e 40 da Resolução no 077/2014-CEE/AP²:

Art. 39 - Constitui infração o não cumprimento desta Resolução e da legislação que garanta os direitos educacionais da criança, do adolescente, dos jovens e adultos, submetendo os infratores à aplicação das sanções previstas nesta Resolução.

Art. 40 - É irregular o funcionamento da instituição educacional que:

I - Inicie suas atividades sem haver solicitado credenciamento e autorização a este CEE/AP;

\footnotetext{
${ }^{2}$ Essa resolução dispõe sobre a criação, credenciamento de instituições de ensino, autorização para funcionamento, reconhecimento e renovação de reconhecimento de etapas e modalidades da educação básica no sistema estadual de ensino do Amapá.
} 
II - inicie suas atividades com pedido de credenciamento e/ou autorização protocolado neste $\mathrm{CEE} / \mathrm{AP}$, antes da respectiva concessão dos atos autorizativos;

III - Inicie atividades de nível/etapa ou modalidade de ensino diverso do que fora autorizado por este CEE/AP;

IV - O prazo de vigência do ato de autorização esteja expirado e não haja protocolado processo de reconhecimento ou renovação do reconhecimento neste CEE/AP (AMAPÁ, 2014, p. 13).

Considerando ainda a Resolução no 077/2014-CEE/AP, os incisos I e II do Art. 44 trata sobre a natureza da infração. Caso constado a infração, o $\mathrm{CEE} / \mathrm{AP}$ poderá aplicar a instituição escolar e/ou aos responsáveis legais, uma ou mais das sanções:

\section{$[\ldots]$}

I - às instituições educacionais: a) Notificação; b) Advertência quando reincidente; c) Suspensão da oferta de anos/séries ou períodos de cursos oferecidos pela instituição com proibição temporária de matricular novos alunos; d) Encerramento compulsório parcial das atividades da instituição educacional, com cassação dos atos outorgados; ou e) Encerramento compulsório total das atividades da instituição educacional, com cassação dos atos outorgados;

II - aos responsáveis legais: a) Notificação por escrito; b) Expedição de recomendação à mantenedora de afastamento do gestor da instituição educacional; c) Representação junto ao Ministério Público Estadual (AMAPÁ, 2014, p. 15).

Além das implicações destacadas, a documentação escolar do estudante é a mais prejudicada, pois quando a escola que está em situação irregular no CEE, a documentação do estudante perde a validade, além de causar prejuízos para vida escolar. E consequentemente, ao recebimento de certificado de conclusão de curso de Ensino Fundamental e Médio. Quando esse problema atinge uma comunidade escolar, os gestores devem procurar ao NIOE/SEED para requerer a emissão de certificação ao corpo discente.

A legislação brasileira e de cada Unidade Federal normatizam sobre a documentação e os que são necessários para regularizar o funcionamento das escolas públicas ou privadas, o que são chamados de atos oficiais. Estes devem ser arquivados nas escolas para consulta, em local de fácil acesso ao público, tendo em vista a Lei de Acesso à Informação - LAI (BRASIL, 2011). 
As escolas públicas ou privadas no Estado do Amapá devem ser regularizadas, obedecendo aos seguintes atos regulatórios: credenciamento, autorização de funcionamento, reconhecimento e renovação de reconhecimento.

Segundo a Resolução no 077/2014-CEE/AP, o credenciamento referese ao ato expresso e específico, pelo qual a SEED cria e admite o compromisso de manter o estabelecimento de ensino de acordo com as normas do sistema estadual de ensino. A criação da escola dar-se-á por meio dos seguintes instrumentos: I - Os mantidos pelo Estado são criados por Decreto do Estado do Amapá; II - Os mantidos pelos municípios são criados por Decreto do Poder Executivo Municipal; III - Os mantidos por pessoas jurídicas de direito privado, são criados por Portaria da mantenedora (AMAPÁ, 2014). Enquanto a autorização de funcionamento é ato oficial em que o poder público permite o funcionamento de atividades educacionais em escolas integradas ao sistema estadual de ensino, sendo concedida pelo prazo determinado de 3 anos. A primeira autorização do estabelecimento de ensino permanece, mesmo que o curso não seja mais ofertado (AMAPÁ, 2014).

Já o reconhecimento é o ato oficial que atesta a legitimidade e as condições plenas para se desenvolver atividades educacionais nas escolas, sendo de responsabilidade do CEE-AP concebé-lo por prazo de 7 anos. Deve ser solicitado em processo próprio, obedecendo ao roteiro, para encaminhamento ao NIOE/SEED e ao CEE-AP/SEED no prazo determinado.

O processo de regularização de uma escola depende dos gestores, da comunidade escolar e do Conselho de Educação para garantir a sua autonomia, a legalidade do seu funcionamento e a expedição de documentos, o implica no direto dos estudantes.

\section{PESQUISA EM EDUCAÇÃO PENITENCIÁRIA, ESTRATÉGIA DE COLETA DADOS E ANÁLISE DOCUMENTAL}

Este trabalho foi desenvolvido pela primeira autora, vinculado ao Curso de Especialização em Docência para a Educação Penitenciária $(\mathrm{Ead})^{3}$, originalmente, com o tema: "Procedimentos para regularização da Escola Estadual

\footnotetext{
3 Ofertado pelo Departamento de Educação a Distância da Universidade Federal do Amapá, Programa Universidade Aberta Brasil e Governo do Estado do Amapá, no Polo Macapá, com financiamento da Coordenação de Aperfeiçoamento de Pessoal de Nível Superior, por intermédio da Diretoria de Educação a Distância - DED/CAPES pelo Edital nº 75/2014.
} 
São José: Uma contribuição à gestão escolar no âmbito da educação penitenciária" (DIAS, 2018), orientado pela segunda autora.

No período de Agosto a Novembro de 2019 realizamos a coleta de dados e a produção da monografia, com base em pesquisa bibliográfica e documental. Tentamos também obter outras informações diretamente no CEE/AP, mas esse órgão da SEED não tinha nenhum documento sobre o tema da pesquisa no seu Arquivo Institucional.

Em virtude deste fato, realizamos uma visita técnica no Núcleo de Inspeção Escolar e Organização - NIOE/SEED, setor responsável pela vida estudantil, onde encontramos 3 atos oficiais: um permanente e dois atos, já vencidos, respectivamente, de criação e as autorizações para oferta de Ensino Fundamental e Ensino Médio (AMAPÁ, 2004, 2009a, 2009b). Além de outra visita técnica na EESJ, momento em que tivemos acesso aos dados educacionais informados por Thatiana de Ameida Pereira, gestora da escola do ano de 2019, que foram anotados no Diário de Campo.

O material selecionado sobre o tema do estudo envolveu legislação, livros, artigos, notícias postadas em Websites, dissertações sobre a educação penitenciária amapaense e os documentos da EESJ. Além de informações em relação ao seu corpo docente, tendo como estratégia para concluir a coleta de dados, a realização de visitas técnicas em três órgãos públicos localizados na capital do Estado do Amapá.

A discussão do resultado foi organizada com base na análise documental. Segundo Cellard (2008), essa análise favorece a observação do processo de maturação ou de evolução de indivíduos, conceitos, grupos, conhecimentos, mentalidades, comportamentos, práticas, entre outros aspectos. Além disso, procuramos evidenciar os dados coletados tanto na produção textual, como também citando fotografias, uma tabela e dois quadros.

\section{RESULTADO DA PESQUISA}

A seguir, apresentamos o resultado, o que descrevemos com base em três categorias de análise, com fim de contextualizar o trabalho desenvolvido pelo corpo docente da EESJ e os seus parceiros para abordar o foco do objeto de estudo. 


\subsection{EESJ: Oferta de cursos da EJA, ações com apoio de parceiros, proje- tos e formatura do ensino médio}

A EESJ foi criada pelo Decreto nำ 1399 de 01 de junho de 2004, quando passou a ser responsável pelos serviços educacionais à população carcerária, o que antes era desenvolvido pelo corpo docente do Centro de Educação de Jovens e Adultos Emílio Médio - CEJAEM e do Centro de Ensino Supletivo Emílio Médici - CESEM, conforme documentado por Abreu (2008) e Vasquez (2008).

É importante dizer que os serviços educacionais prestados pela equipe docente da EESJ a partir de 2004, continuaram sendo no mesmo prédio do CEJAEM, que estava dentro da área de sergurança da penitenciária. Durante a gestão escolar de Raimundo Aldo Siqueira (2011-2015), algumas mudanças ocorreram, considerando que:

O referido gestor promoveu a criação da secretaria escolar, continuidade na execução da segunda fase do Projeto Construindo a Qualificação Profissional para (Re)socialização de Apenados, proporcionou melhorias na parte de ambientação escolar, como por exemplo, criação do jardim em frente da escola, da sala dos professores, secretaria escolar, banheiros para funcionários, sala da coordenação pedagógica, além de instituir a vestimenta de uniformes para o corpo discente e docente (AMAPÁ, 2014, p. 23).

A reforma realizada no prédio da escola, que se refere essa citação pode ser comprovada pela Figura 1.

Figura 1 - Frente da EESJ após a reforma do prédio

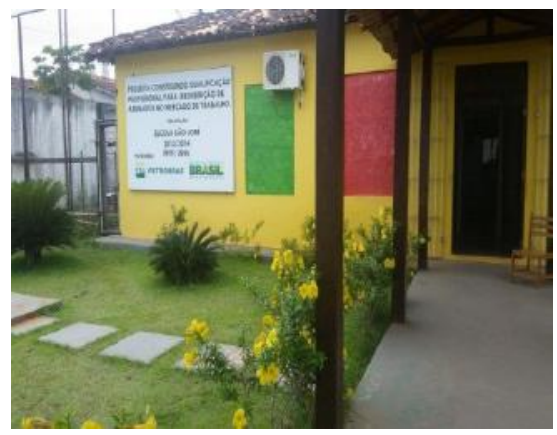

Fonte: (AMAPÁ, 2016). 
A autorização de funcionamento da EESJ para oferta de curso de Ensino Fundamental foi obtida pela Portaria no 139/2009-SEED, bem como pela Portaria $n^{\circ} 140 / 2009-S E E D$, que autorizou o funcionamento do Ensino Médio, ambas pela modalidade de EJA (AMAPÁ, 2009a, 2009b). No ano de 2019, a escola atendeu 320 estudantes, sendo 193 no Ensino Fundamental e 127 no Ensino Médio. O Ensino Fundamental estava dividido em 9 turmas, sendo: 2 turmas na $1^{\text {a }}$ Etapa, 2 turmas na $2^{\text {a }}$ Etapa, 2 turmas na $3^{\text {a }}$ Etapa, 3 turmas na $4^{\text {a }}$ Etapa. Essas turmas foram formadas por 151 adultos presos e 42 adultas presas. Enquanto que no Ensino Médio, foram 3 turmas da $1^{\text {a }}$ Etapa e 2 turmas da $2^{a}$ Etapa, totalizando 97 adultos presos e 30 adultas presas, conforme anotado no Caderno de Campo.

Com base em notícia do website do Tribunal de Justiça do Amapá TJAP, sabemos que em 2017, outras ações foram desenvolvidas na EESJ, como um Programa de Mediação pela equipe do Núcleo Permanente de Métodos Consensuais e Solução de Conflitos - NUPEMEC, formada por servidores do TJAP, professores da EESJ e participação de adultos presos (Figura 2), com objetivo de: “[...] trabalhar principalmente na prevenção de conflitos, que no presídio ocorrem de forma intensa, em razão da pressão proveniente da situação em que se encontram os presos" (TJAP, 2017), que chegou a concorrer a $14^{a}$ edição do Prêmio Innovare, que reconhece o êxito de práticas do Poder Judiciário, do Ministério Público, da Defensoria Pública e dos advogados.

Figura 2 - Uma parte da equipe do NUPEMEC na EESJ

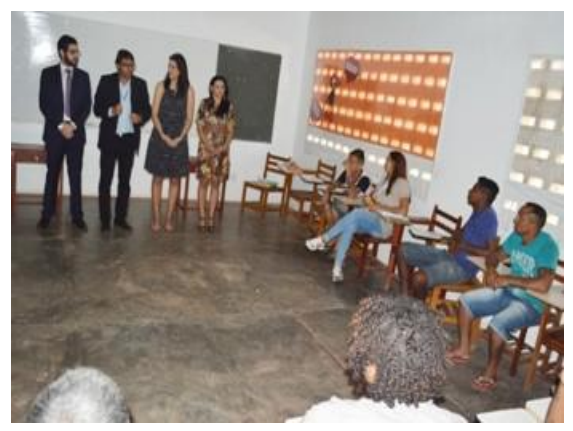

Fonte: (TJAP, 2017).

"Os próprios detentos auxiliam na conciliação após passarem por treinamento proporcionado pelo NUPEMEC. É uma forma de incluí-los nas atividades para que eles disseminem essa cultura de pacificação e urbanidade entre os demais detentos", conforme esclarece a notícia (TJAP, 2017). 
Ainda no ano de 2017, a equipe do núcleo trabalhou com palestras e oficinas educativas sobre mediação de conflitos, que aconteceram no final de cada mês. Outra importante ação desenvolvida na EESJ como parte da programação escolar, foi o projeto: Construindo Qualificação Profissional para a (Re)inserryão de Apenados no Mercado de Trabalho, que foi executado no período de 2009 até novembro de 2011, com objetivo de ofertar cursos para adultos presos, envolvendo homens e mulheres presas (AMAPÁ, 2014, 2017; ALVES, 2016), o que ilustramos com a Figura 3.

Figura 3 - Projeto oferta cursos profissionalizantes para detentos do IAPEN

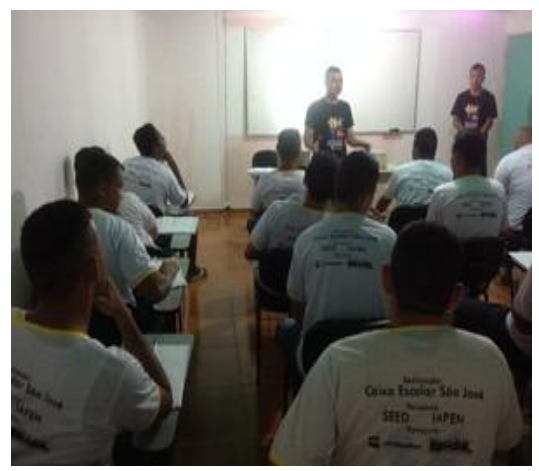

Fonte: (ALVES, 2016).

A $2^{a}$ fase desse projeto iniciou em 2014 e deveria encerrar em julho de 2015. "Mas, segundo Francinete Cardoso, foi solicitado um aditivo de tempo para dar continuidade às capacitações e assim evitar perdas de recursos [financeiros]", conforme (ALVES, 2016). Ainda nesse ano, a EESJ recebeu visita técnica de Marco Firmino dos Santos (gestor de projetos sociais da PETROBRÁS) e a escola aguardava a liberação de verbas para próxima etapa do projeto, o que foi informado pela gestora da EESJ numa notícia do Website do G1.

Ainda, a notícia do Website do G1 divulgou com relação a $2^{a}$ fase desse projeto, que foram ofertados os seguintes cursos: "montagem e manutenção de computadores, cabeleireiro, microempreendedor e serigrafia. Além disso, também abrirão turmas para os cursos de horticultor de legumes, pintor de obras, informática básica, noções de jardinagem e paisagismo e garçom” (ALVES, 2016). A EESJ formou 15 adultos presos, que concluíram o Ensino Médio no ano de 2018 (Figura 5) e a sua cerimônia de colação de grau foi divulgada entre as notícias do Webiste do G1. Eles tiveram a oportunidade de continuar os seus estudos pelo curso ofertado por uma escola pública, na cidade de Macapá (VIDIGAL, 
POLLYNE, SOUSA, 2019). Esse número representa um percentual baixo em relação à população carcerária, pois cerca de $70 \%$ dos presos não concluem os estudos, conforme dados do IAPEN (Ibid., 2019).

Figura 5 - Formatura/2018 da EESJ

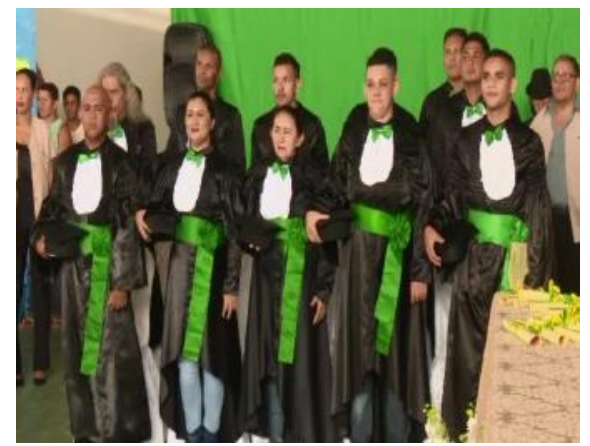

Fonte: Fotografia de Victor Vidigal, citada por VIGIGAL, POLLYNE, SOUSA, 2019.

O Coordenador do Tratamento Penal, José Antônio Nunes comentou nessa notícia que: "A cada três dias de aula, o que representa 12 horas, elimina um dia na pena desse preso. Não só essa remissão de pena, mas o estudo atribui conhecimento, capacitação e qualificação desse jovem que está no sistema prisional", conforme citado por Vidigal, Pollyne e Sousa (2019) e que se fundamenta na Lei $\mathrm{n}^{\text {o }}$ 12.433/2011 em vigor no Brasil, que trata da remição de parte do tempo de execução da pena por estudo ou por trabalho (BRASIL, 2011) e anteriormente pela Portaria $n^{\circ}$ 009/2005 emitida pela VEP/TJAP (VASQUEZ, 2008; ABREU, 2008).

\subsection{Documentação para regularizar a EESJ e seu recurso humano em 2019}

Quando uma escola está em situação irregular no CEE, a documentação para encaminhar o pedido de Reconhecimento das Etapas ou modalidades de Ensino à SEED, deve ser protocolado em posse da seguinte documentação:

Ofício de solicitação de Reconhecimento das etapas e/ou modalidades da Educação Básica ofertadas; Projeto Político Pedagógico; Matriz Curricular; Sistemática de Avaliação; Quadro administrativo, técnico e docente devidamente habilitado na forma da lei; Regimento Escolar; Cópia do comprovante do Censo Escolar dos últimos 3 anos; Relação do corpo administrativo, técnico e 
docente, acompanhado de cópia do comprovante da habilitação legal de cada profissional (AMAPÁ, 2014).

A SEED por meio do NIOE, realizou uma visita técnica na EESJ, em abril de 2019, para orientar a equipe de gestão da escola, quanto a sua situação irregular no CEE, o que foi informado pela gestora da escola e anotado no Caderno de Campo.

$\mathrm{O} \int 1^{\circ}$ do Art. $5^{\circ}$ da Resolução n⿳0 057/2015-CEE/AP regulamentou sobre a formação dos professores que trabalham na EESJ e gratificação a esse grupo de docentes:

\section{$[\ldots]$}

$\mathbb{S} 1^{\circ}$ Os docentes que atuam nos espaços penais deverão ser profissionais do magistério devidamente habilitados e com remuneração condizente com as especificidades da função, podendo auferir uma gratificação adicional, considerando a natureza do trabalho, como está estabelecida nas diretrizes do Conselho Nacional de Políticas Criminais e Penitenciária CNPCP e do Conselho Nacional de Educação - CNE (AMAPÁ, 2015, p. 3).

Há que se considerar ainda que o Art. 61 da LDBN normatiza que a formação de profissionais da educação deve atender aos objetivos dos diferentes níveis e modalidades de ensino e as características de cada fase do desenvolvimento do estudante (BRASIL, 1996).

Logo, a formação de docentes para trabalhar na Educação Básica exige habilitação em Curso de Licenciatura, que são ofertados pelas Instituições de Ensino Superior ${ }^{4}$.

Em 2019, o recurso humano da escola era formado por 46 docentes (Tabela 1), tendo professores do Ensino Fundamental I que ensinavam todas as disciplinas nas turmas de $1^{\underline{a}}$ e $2^{\underline{a}}$ Etapas do curso de EJA, do Ensino Fundamental II e do Ensino Médio que lecionam as disciplinas que são devidamente habilitados ou que em caso de necessidade por falta de professores, às vezes eles são convidados em caráter excepcional, a ministrá-las.

\footnotetext{
4 Admiti-se como formação inicial mínima o Curso de Magistério para trabalhar na Educação Infantil ou Ensino Fundamental II. Enquanto que para o Ensino Fundamental II e Ensino Médio o professor deve ter o diploma de Licenciatura em disciplinas específicas.
} 
Tabela 1 - Professores lotados na EESJ - Macapá / 2019

\begin{tabular}{|c|c|c|c|}
\hline Professor & Quantitativo & $\begin{array}{c}\text { Trabalhando } \\
\text { na sala de } \\
\text { aula }\end{array}$ & $\begin{array}{c}\text { Trabalhando } \\
\text { em outro ambiente }\end{array}$ \\
\hline $\begin{array}{c}1^{\mathrm{a}} \text { e } 2^{\mathrm{a}} \text { Etapas do Ensino } \\
\text { Fundamental I }\end{array}$ & 15 & 7 & 8 \\
\hline Língua portuguesa & 4 & 4 & 0 \\
\hline Matemática & 3 & 2 & 1 \\
\hline Ciências & 0 & 0 & 0 \\
\hline História & 2 & 2 & 0 \\
\hline Geografia & 2 & 2 & 0 \\
\hline Artes & 2 & 1 & 1 \\
\hline Inglês & 1 & 1 & 0 \\
\hline Espanhol & 0 & 0 & 0 \\
\hline Química & 2 & 2 & 0 \\
\hline Física & 1 & 1 & 0 \\
\hline Biologia & 2 & 2 & 0 \\
\hline Educação Especial & 3 & 3 & 0 \\
\hline Ensino Religioso & 1 & 0 & 1 \\
\hline Didática & 2 & 1 & 1 \\
\hline Filosofia & 1 & 1 & 0 \\
\hline Sociologia & 1 & 1 & 0 \\
\hline Pedagogo & 2 & 0 & 2 \\
\hline Educação Física & 2 & 2 & 0 \\
\hline Total & 46 & 32 & 14 \\
\hline
\end{tabular}

Fonte: Elaborado pelas autoras, com base em informações obtidas com a gestora da EESJ.

Considerando a Resolução nº 056/2011-CEE/AP (AMAPÁ, 2011) e o total de 46 professores lotados em 2019 na EESJ (Tabela 1), que trabalham com planejamento e ensino em cursos da EJA na educação penitenciária. Os dados revelam, que em 2019, a escola não tinha professor de Espanhol e Ciências. Mas tinha no seu quadro docente, dois professores da disciplina de Didática, cuja disciplina não faz parte da matriz curricular dos cursos ofertados aos adultos presos.

Um dos professores de Didática, trabalhava na turma da 2a Etapa e outro no Laboratório de Informática e Educacional - LIED, conforme esclarecido 
pela gestora escolar. O LIED tinha dez computadores, sendo nesses instalados o Sistema Operacional LINUX. Mas os computadores do LIED não têm acesso à internet.

\subsection{Discussão do resultado}

Com base na leitura e análise da Portaria nº 139/2009-SEED e da Portaria no 140/2009-SEED (AMAPÁ, 2009a, 2009b), constatamos que em 2019, a EESJ estava com os atos de autorização de funcionamento vencidos há quase 10 anos, o que obriga a gestora da escola a solicitar ao NIOE/SEED, a emissão de certificados de conclusão de Cursos de Ensino Fundamental e Médio.

A gestora da escola informou que a equipe pedagógica e de gestão tem interesse e pretende elaborar o novo Regimento da EESJ, com o apoio do corpo docente e dos estudantes. Além de desejar atualizar a sua Sistemática de Avaliação e Matriz Curricular, com o fim de atender as necessidades dos adultos presos e estudantes. Mas em 2019, a gestora ainda não tinha uma previsão para conclusão, dados que foram anotados no Caderno de Campo.

Outro aspecto da análise do objeto de estudo, com base no PEESP/ $\mathrm{AP}$, pode-se verificar que a EESJ, ainda não tem um Projeto PolíticoPedagógico - PPP (AMAPÁ, 2014; 2017). Esses dois PEESP/AP indicam algumas especificidades a serem consideradas no debate e na elaboração/aprovação do seu PPP.

Por exemplo, a questão de manter a segurança no ambiente carcerário e no local de trabalho para que os serviços educacionais sejam prestados, a necessidade de critérios para formar as turmas nos cursos ofertados pela equipe da EESJ, a diversidade cultural no sistema penitenciário, o que se manisfesta pela "cultura escolar e cultura prisional” (VASQUEZ, 2008), devido o convívio na EESJ entre professores, estudantes presos e agentes penitenciários. Além disso, os PEESP/AP defendem a oferta de cursos aos adultos presos, com base numa concepção que entende e reconhece que a educação penitenciária como direito social e humano para promover a Cultura de Paz, a Inclusão Social e a Cidadania (AMAPÁ, 2014, 2017).

Foram definidos na Seção 5.2. Regras e procedimentos de rotina do Capítulo 5. Gestão do PEESP/AP de 2017, como parte das suas ações prioritárias: 


\section{PLANO DE AÇÃO}

a) Articular, no prazo de 2 (dois) anos, as medidas necessárias para a elaboração de um documento normativo, com valor oficial, que discipline as práticas de segurança dentro das instituições penais, que contemple principalmente regras e procedimentos de rotina das ações para o pleno funcionamento da assistência escolar e afins.

b) Elaborar, no prazo de 1 (um) ano, Projeto Pedagógico Institucional, documento destinado a definir diretrizes e práticas educacionais para o sistema prisional do Amapá.

c) Articular, no prazo de 2 (dois) anos, a partir desta publicação, a elaboração do Projeto Pedagógico e do Regimento Interno da Escola Estadual São José [...] (AMAPÁ, 2017, p. 49).

O fato de constar escrito no PEESP/AP a necessidade de elaborar o Projeto Pedagógico Institucional, o Projeto Político-Pedagógico e Regimento Escolar indicam que algumas das demandas recorrentes da EESJ foram bastante discutidas no período de elaboração do Plano. Mas com base em informações obtidas na visita técnica na EESJ, segundo a gestora escolar, esse importante documento da política educacional no Estado do Amapá ainda não foi aprovado pela Assembleia Legislativa do Amapá, como deveria já ter acontecido, como ocorreu com o Plano Estadual de Educação - PEE, por meio da Lei no 1.907 de 24 de junho de 2015 para os decênios de 2015-2025 (AMAPÁ, 2015).

Portanto, a EESJ ainda não tem o seu Projeto Político-Pedagógico. Entretanto, essa não é a única dificuldade que a impede de regularizar a escola no CEE-AP, pois outro critério é que ela necessita atualizar o seu censo escolar.

O censo escolar é uma pesquisa sobre a educação básica, que é realizado em cada ano pelo Instituto Nacional de Estudos e Pesquisas - INEP, com o fim de sistematizar o diagnóstico da situação das escolas (BRASIL, 2008). Portanto, as suas informações e dados estatísticos são essenciais para o planejamento, a execução e o acompanhamento das políticas educacionais no sistema educacional e no sistema penitenciário. A sua coleta de dados permite aos gestores das instituições escolares conhecer os pontos fortes e fracos dos serviços educacionais ofertados à comunidade estudantil.

A gestora da EESJ, durante a visita técnica deste estudo, relatou que a escola estava com dificuldade em finalizar o Censo Escolar do ano de 2018, devido à modificação do Calendário Escolar. Esses dados educacionais devem ser informados ao INEP, pois sua missão "é subsidiar a formulação de políticas ed- 
ucacionais dos diferentes níveis de governo com intuito de contribuir para o desenvolvimento econômico e social do país" (INEP, 2019).

Considerando a análise documental, avaliamos que cabe orientar e lembrar a equipe de gestão da escola, quanto à necessidade de priorizar a regularização da EESJ no CEE, com base nas orientações e nos procedimentos, que são recomendados pelo NIOE, como:

- Orientação $\mathbf{n}^{0}$ 1: A equipe da gestão escolar deve priorizar a regularização da EESJ, como parte das suas demandas recorrentes, ou seja, problemas que existem há um certo tempo e que se inserem no desenvolvimento da política pública e que ainda não foram resolvidas, interpretação que fazemos, a partir de Croce e Roggero (2015).

O Ato de Reconhecimento é importante para o funcionamento da escola e qualidade dos serviços educacionais prestados aos adultos presos, assim como o Regimento Escolar. Quanto à Sistemática de Avaliação e a Matriz Curricular, a EESJ já cumpre esses dois critérios, com base na Resolução ${ }^{\circ}$ 056/2011-CEE/AP, assim como as demais escolas da rede estadual (AMAPÁ, 2011).

- Orientação $\mathbf{n}^{\circ}$ 2: A equipe da gestão escolar pode utilizar os documentos que a escola já tem para requerer a sua regularização no CEE (Quadro 1), para protocolar o Ofício que deve ser encaminhado à SEED.

Quadro 1 - Documentos que a EESJ tem em arquivo institucional

\begin{tabular}{|c|c|c|}
\hline \multirow{2}{*}{ Descrição } & \multicolumn{2}{|c|}{ Resposta } \\
\cline { 2 - 3 } & Sim & Não \\
\hline Regimento Escolar & $\mathrm{X}$ & \\
\hline Matriz Curricular & $\mathrm{X}$ & \\
\hline Sistemática de Avaliação & $\mathrm{X}$ & \\
\hline $\begin{array}{c}\text { Relação do corpo docente, técnico } \\
\text { e de gestão }\end{array}$ & $\mathrm{X}$ & \\
\hline $\begin{array}{c}\text { Cópias dos certificados que com- } \\
\text { provem a formação acadêmica e habili- } \\
\text { tação do recurso humano }\end{array}$ & $\mathrm{X}$ & \\
\hline
\end{tabular}

Fonte: Elaborado pelas autoras, com base em informações coletadas no NIOE/SEED. 
Essa orientação do NIOE justifica-se para garantir a celeridade da tramitação do processo administrativo no Sistema Integrado de Atendimento ao Cidadão na SEED.

- Orientação $\mathbf{n}^{\circ}$ 3: A equipe de gestão da EESJ deve providenciar a elaboração dos documentos ausentes (Quadro 2), uma vez que sem o PPP e as cópias do Censo Escolar dos últimos três anos, não será possível regularizar a escola no CEE.

Quadro 2 - Documentos que a EESJ não tem em arquivo institucional

\begin{tabular}{|c|c|c|}
\hline \multirow{2}{*}{ Descrição } & \multicolumn{2}{|c|}{ Resposta } \\
\cline { 2 - 3 } & Sim & Não \\
\hline Projeto Político-Pedagógico - PPP & & $\mathrm{X}$ \\
\hline $\begin{array}{c}\text { Cópias do Censo Escolar dos três } \\
\text { últimos anos }\end{array}$ & & $\mathrm{X}$ \\
\hline
\end{tabular}

Fonte: Elaborado pelas autoras, com base em informações coletadas no NIOE/SEED.

A equipe de gestão da EESJ deve também ter como prioridade no seu Calendário Escolar produzir o PPP, assim como atualizar o Censo Escolar e informá-lo ao INEP, considerando que sem esses documentos a escola fica impedida de tramitar formalmente o pedido para regularizar-se no CEE.

Nesse contexto, compete ao CEE atuar na fiscalização e no acompanhamento quanto à aplicação das leis e das resoluções pelas escolas (AMAPÁ, 2014), devendo articular-se com a SEED, com os Conselhos Municipais de Educação e os órgãos do TJAP e do IAPEN, que desenvolvem ações em defesa e garantia dos direitos dos adultos presos de estudar.

Com relação ao foco deste estudo, constatamos que a EESJ tem ato de criação, o Decreto no 1399 de 01 de junho de 2004 (AMAPÁ, 2004), ou seja, ela já possui um ato oficial importante. Também têm os atos de autorização de funcionamento para o Ensino Fundamental, a Portaria nº 139/2009-SEED e para o funcionamento do Ensino Médio, a Portaria no 140/2009-SEED. Além da Resolução no 057/2015-CEE/, que trata da oferta de cursos pela EJA aos adultos presos (AMAPÁ, 2004, 2009a, 2009b, 2015).

O Regimento Escolar em vigor na EESJ é o regimento padrão da SEED (AMAPÁ, 2015). Nele consta a organização administrativa, pedagógica e disciplinar das escolas da rede estadual de ensino do Estado do Amapá, como os seus objetivos gerais. Esse documento foi aprovado pela Resolução ${ }^{\circ}$ 
046/2015-CEE/AP e se referencia na legislação educacional vigente, sendo parte dos seus princípios:

[...] Desenvolver o processo educativo fundamentado no princípio da participação efetiva da família e da comunidade; Oportunizar experiências que contribuam para o exercício da cidadania, através da participação da comunidade escolar em Órgãos Colegiados e na Gestão Democrática da escola (AMAPÁ, 2015, p. 27).

Contudo, ressaltamos a importância da EESJ ter o Regimento Escolar próprio para valorizar as especificidades do grupo de estudantes atendidos pela escola dentro da prisão, na cidade de Macapá, que são homens presos, que estão de regime fechado ou que estão custodiados no IAPEN, e também mulheres presas ou detidas provisoriamente na COPEF. Considerando a prioridade de regularizar o seu funcionamento, a escola pode optar em continuar por um determinado tempo pelo uso do Regimento Padrão da mantenedora.

A sistemática de avaliação da EESJ é a mesma adotada pela SEED e baseia-se nas concepções Qualitativa, Mediadora, Processual, Progressista, Libertadora, Contínua e Redimensionadora, em consonância com a Resolução $\mathrm{n}^{\mathrm{o}}$ 07/2010-CNE (BRASIL, 2010) e compreende a avaliação como elemento integrador entre a aprendizagem e o ensino.

Considera ainda os princípios de atendimento à diversidade, a escola deve tentar oportunizar um trabalho interdisciplinar para tornar a aprendizagem significativa ao corpo discente, com base nas lógicas formativa e somativa (AMAPÁ, 2015). A primeira, preocupa-se com o processo de apropriação dos saberes pelo estudante, mediados pela intervenção do professor, para promover a regulação das aprendizagens, revertendo a eventual rota do fracasso e reinserindo o estudante no processo educativo. Enquanto que, a outra apoia-se numa concepção classificatória de avaliação, cuja função ao término de cada unidade temática, semestre ou ano letivo, é a de verificar se houve aquisição de conhecimento (Ibid., 2015).

O regimento escolar e a sistemática de avaliação foram aprovados pela Resolução no 046/2015-CEE/AP. Considerando ainda, o espaço e as limitações em que a EESJ está inserida, faz-se necessária uma Sistemática de Avaliação própria, por ser a única escola pública que oferta cursos de ensino fundamental e médio às pessoas privadas de liberdade, além de atuar com projetos, com apoio de colaboradores e parceiros. 
A sua sistemática de avaliação, em 2019, ainda não contemplava as especificidades da EJA na Educação Penitenciária. Contudo, depois que a EESJ estiver em situação regular no CEE, ela terá o tempo necessário para a construção de uma sistemática própria, por ser a única escola que atua no cárcere no Estado do Amapá.

A matriz curricular da EESJ é a mesma adotada pela SEED, que foi aprovada pela Resolução n⿳o 056/2011-CEE/AP, o que destacamos:

Art. 18 - São componentes curriculares integrantes da Base Nacional Comum, articulados com as Áreas de conhecimento, no Ensino Fundamental: I) Linguagens: Língua Portuguesa; Língua Materna para População Indígena; Língua Estrangeira Moderna; Artes; Educação Física. II) Matemática; III) Ciências da Natureza; IV) Ciências Humanas: Geografia; História. V) Ensino Religioso.

Art. 19 - Os componentes curriculares integrantes da Base Nacional Comum para o Ensino Médio serão agrupados nas áreas do conhecimento, objetivando constituição de competências e habilidades, conforme o disposto a seguir: I - Linguagens: a) Língua Portuguesa/Literatura; b) Língua Materna para populações indígenas; c) Língua Estrangeira moderna; d) Artes, em suas diferentes linguagens: cênicas, plásticas e, obrigatoriamente, a musical; e) Educação Física. II - Matemática; III - Ciências da Natureza: Biologia; Física; Química; III - Ciências Humanas: História; Geografia; Filosofia; Sociologia (AMAPÁ, 2011, p. 4).

A EESJ ainda não tem uma matriz curricular própria que atenda às necessidades da comunidade escolar-prisional ou dos adultos presos, que venham suprir as demandas recorrentes da EJA na Educação Penitenciária, e que considere o encarceramento e o confinamento de humanos no seu planejamento de ensino e de projetos.

\section{CONCLUSÃO}

No Estado do Amapá, o acesso à educação escolar no cárcere é garantido apenas pela oferta de curso pela modalidade EJA, na cidade de Macapá, sendo o seu corpo docente formado pelos servidores públicos da SEED, lotados na EESJ.

Concluímos, com base na análise documental que em 2019, a EESJ estava em situação irregular no CEE, pois os seus atos de autorização para funci- 
onamento estavam vencidos, o que a impede de emitir os certificados aos concluintes de cursos de Ensino Fundamental e Médio desde 2004.

Para que a escola deixe de estar irregular no CEE, é essencial que a equipe de gestão priorize a documentação da EESJ que falta, visando atender os critérios que determinam a legislação educacional, o que significa elaborar o seu Projeto Político-Pedagógico, com a participação do corpo administrativo da escola e da penitenciária, do corpo docente e discente, além de providenciar a atualização do Censo Escolar.

O resultado do estudo aponta informações sobre os projetos e as ações de 2009 a 2017, a formatura do Ensino Médio de 2018, o recurso humano da EESJ de 2019, a quantidade de estudantes atendidos em 2019 e sobre os seus atos de criação e de funcionamento para oferta de cursos de Ensino Fundamental e Médio pela EJA na educação penitenciária.

A ausência de Projeto Político-Pedagógico e do Censo Escolar indicam duas demandas decorrentes da escola instalada na prisão, que dificultam a tramitação de processo administrativo para regularizá-la na SEED. Essas demandas recorrentes são problemas reais da política educacional, que existem e que não foram priorizados e nem resolvidos entre os problemas da educação pública amapaense.

\section{REFERÊNCIAS}

ABREU, A. A. Educação entre grades: um estudo sobre educação penitenciária no amapá. 2008. Dissertação (Mestrado em Educação) - Universidade Federal de São Carlos, São Carlos, 2008.

ALMEIDA, M. S. S.; SILVA, E. P.; VASQUEZ, L. E. Carta da educação penitenciária amapaense. Macapá, 2018.

ALVES, J. Um novo caminho', diz detento que participa de profissionalização no AP. 25 de maio de 2016. Disponível em: < http://g1.globo.com/ap/amapa/noticia/ 2016/05/um-novo-caminho-diz-detento-que-participa-de-profissionalizacaono-ap.html.> Acesso: 09 de Ago. 2019.

AMAPÁ. Cópia do Decreto no 1399 de 01 de junho de 2004. Estabelece a criação da Escola Estadual São José como parte do Complexo Penietenciário. Macapá, 2004. (Arquivo Institucional do NIOE/SEED).

Cópia da Portaria no 139/2009-SEED. Macapá, 2009a. (Arquivo Institucional do NIOE/SEED). 
Cópia da Portaria no 140/2009-SEED. Macapá, 2009b. (Arquivo Institucional do NIOE/SEED).

. Resolução no 056/2011-CEE/AP. Aprova as Diretrizes Curriculares, Plano Curricular e Matrizes Curriculares da Educação Básica da Rede Estadual de Ensino no Amapá. Diário Oficial do Estado no 5058. Macapá, 01 de setembro de 2011.

. Resolução no 077/2014-CEE/AP. Dispõe sobre a criação, credenciamento de instituições de ensino, autorização para funcionamento, reconhecimento e renovação de reconhecimento de etapas e modalidades da educação básica do sistema estadual de ensino do Amapá e estabelece outras providências. Diário Oficial do Estado no 5926. Macapá, 07 de abril de 2015.

. Plano estadual de educação para o sistema penitenciário do amapá. Macapá, 2014.

. Plano Estadual de Educação para o Sistema Penitenciário do Amapá. Macapá, 2017.

Resolução n⿳o 046/2015-CEE/AP. Homologa o regimento escolar e a sistemática de avaliação da rede estadual de ensino. Diário Oficial do Estado no 5979. Macapá, 19 de junho de 2015.

. Resolução nº 057/2015-CEE/AP. Dispõe sobre a oferta da Educação de Jovens e Adultos e da Educação Profissional e Tecnológica para pessoas privadas de liberdade, nos estabelecimentos penais do estado do Amapá e dá outras providências correlatas. Diário Oficial do Estado no ${ }^{\circ}$ 6134. Macapá, 15 de fevereiro de 2016.

Lei no 1.907 de 24 de junho de 2015. Dispõe sobre o Plano Estadual de Educação - PEE, para o decênio 2015-2025, e dá outras providências. Disponível em: <http://www.mpap.mp.br/.> Acesso: 09 ago. 2019.

. Internos do Iapen ganham oportunidade de qualificação profissional. 26 de julho de 2016. Disponível em: < $\underline{\text { http://www.portal.ap.gov.br/ }}$ ler noticia.php?slug=0108/internos-do-iapen-ganham-oportunidade-de-qualificacao-profissional.> Acesso em: 09 ago 2019.

BRASIL. Lei no 7210/84. Instituiu a Lei de Execução Penal. Disponível em: < https://www2.camara.leg.br/legin/fed/lei/1980-1987/lei-7210-11-julho1984-356938-publicacaooriginal-1-pl.html> Acesso: 09 ago. 2019 
Constituição da República Federativa do Brasil: texto constitucional promulgado em 5 de outubro de 1988, com as alterações determinadas pelas Emendas Constitucionais de Revisão nos 1 a 6/94, pelas Emendas Constitucionais nำ1/92 a 91/2016 e pelo Decreto Legislativo no 186/2008. Brasília: Senado Federal, Coordenação de Edições Técnicas, 2016.

. Decreto $\mathbf{n}^{\mathbf{0}} \mathbf{6 . 4 2 5}$ de 4 de abril de 2008. Dispõe sobre o censo atual da educação. Disponível em: < http://www.planalto.gov.br/ccivil 03/ Ato2007-2010/2008/Decreto/D6425.htm > Acesso: 09 ago. 2019

. Resolução no 02/2010-CNE/CEB. Dispõe sobre as Diretrizes Nacionais para a oferta de educação para jovens e adultos em situação de privação de liberdade nos estabelecimentos penais. Disponível em: < $\underline{\text { http://www12.se- }}$ nado.leg.br/institucional/biblioteca $>$ Acesso em: 09 ago. 2019.

. Resolução no 7 de 14 de dezembro de 2010. Fixa Diretrizes Curriculares Nacionais para o Ensino Fundamental de 9 (nove) anos. Disponível em: $<$ http://portal.mec.gov.br/dmdocuments/rceb007 10.pdf $>$ Acesso: 09 ago. 2019.

Lei no $\mathbf{1 2 . 4 3 3 / 2 0 1 1 . ~ A l t e r a ~ a ~ L e i ~ n o ~} 7.210$ de 11 de julho de 1984 (Lei de Execução Penal), para dispor sobre a remição de parte do tempo de execução da pena por estudo ou por trabalho. Brasília, 29 de julho de 2011. Disponível em: < http://bd.camara.gov.br.> Acesso em: 09 ago. 2019.

. Lei $\mathrm{n}^{\circ} \mathbf{1 2 . 5 2 7}$ de 18 de novembro de 2011. Regula o acesso a informações previsto no inciso XXXIII do art. $5^{\circ}$, no inciso II do $\$ 3^{\circ}$ do art. $37 \mathrm{e}$ no $₫ 2^{\circ}$ do art. 216 da Constituição Federal; altera a Lei no ${ }^{\circ} .112$, de 11 de dezembro de 1990; revoga a Lei no 11.111, de 5 de maio de 2005, e dispositivos da Lei oㅡㅇ 8.159, de 8 de janeiro de 1991; e dá outras providências. Disponível em: <http://www.planalto.gov.br/ccivil_03/_ato2011-2014/2011/lei/

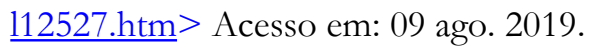

. Lei $\mathbf{n}^{\circ} \mathbf{1 3 . 1 6 3}$ de $\mathbf{9}$ de setembro de 2015. Modifica a Lei $\mathrm{n}^{\mathrm{o}} \mathbf{7 . 2 1 0}$ de 11 de julho de 1984 - Lei de Execução Penal, para instituir o ensino médio nas penitenciárias. Disponível em: < http://www.planalto.gov.br/ccivil 03/ Ato2015-2018/2015/Lei/L13163.htm> Acesso em: 09 ago. 2019.

CELLARD, A. A análise documental. In: POUPART, J.; DESLAURIERS, J-P.; GROULX, L-H.; LAPERRIÈRE, A.; MAYER, R.; PIRES, A. P. A pesquisa qualitativa: enfoques epistemológicos e metodológicos. Petrópolis: Vozes, 2008. p. 296-316. 
CROCE, M. L.; ROGGERO, R. Notas sobre Política, Políticas Públicas e seu Significado para Pensar o Tempo-Memória em Educação. In: BAPTISTA, A. M. H.; ROGGERO, R.; MAFFRA, J. (Org.). Tempo-Memória: Perspectivas em educação. São Paulo: BT Acadêmica, 2015. p. 263-279.

\section{DIAS, Z. R. Procedimentos para regularização da Escola Estadual São}

José: uma contribuição à gestão escolar no âmbito da educação penitenciária. 2019. Monografia (Especialização em Docência para Educação Penitenciária ) Universidade Federal do Amapá, Macapá, 2019.

DUARTE, A. J. O.; SIVIERI-PEREIRA, H. O. Aspectos históricos da educação escolar nas instituições prisionais brasileiras do período imperial ao século XXI. Educação Unisinos, São Leopoldo, Vol. 22, n. 4, p. 344-352, Out./Dez. 2018.

INSTITUTO NACIONAL DE ESTUDOS E PESQUISAS EDUCACIONAIS ANÍSIO TEIXEIRA. Conheça o INEP. Disponível em: <http://portal.inep.gov.br/conheca-o-inep>Acesso em: 09 ago. 2019 .

ONOFRE, E. M. C.; JULIÃO, E. F. A Educação na Prisão como Política Pública: entre desafios e tarefas. Educação \& Realidade, Porto Alegre, Vol. 38, n. 1, p. 51-69, Jan./Mar. 2013.

SILVA, R.; OLIVEIRA, C. B. F.; BITENCOURTH, C. S.; ZAMBONI, M. R. G.; MENDES, P. A Educação em Prisões e o Papel da Universidade Pública. Rev. Cult. Ext. USP, São Paulo, Vol. 17, p. 65-80, Mai. 2017.

UNIVERSIDADE FEDERAL DO AMAPÁ. Ofício nº 02/2017-NAI/ PROEAC/UNIFAP. Macapá, 2017.

VASQUEZ, E. L. Sociedade cativa. Entre cultura escolar e cultura prisional: uma incursão pela ciência penitenciária. 2008. Dissertação (Mestrado em História da Ciência) - Pontifícia Universidade Católica de São Paulo, São Paulo, 2008.

VIDIGAL, V.; POLLYNE, N.; SOUSA, A. Voltei a sonhar', diz preso por homicídio em formatura de escola dentro de prisão no AP. 09 de abril de 2019. G1. Disponível em: < http://g1.globo.com/ap/amapa/noticia/2019/04/09/volteia-sonhar-diz-preso-por-homicidio-em-formatura-de-escola-dentro-de-prisaono-ap.ghtml> Acesso em: 09 ago. 2019. 
XAVIER. E. D.; SILVA, R. C. Educação no cárcere: análise comparativa das legislações brasileira e argentina. Direito, Estado e Sociedade, Rio de Janeiro, n. 50, p. 86-108, Jan./Jun. 2017. 